This article is licensed under the Creative Commons Attribution-NonCommercial 4.0 International License (CC BY-NC) (http://www.karger.com/Services/OpenAccessLicense) Usage and distribution for commercial purposes requires written permission.

\title{
Emergency Foramen Magnum Decompression for Tonsillar Herniation Secondary to Meningoencephalitis
}

\author{
Fardad T. Afshari ${ }^{a} \quad$ Barbara Wysota $^{\mathrm{b}}$ Michelle Oswal ${ }^{\mathrm{b}}$ \\ Gordan Mazibradab Edward A. White ${ }^{a}$ \\ aDepartment of Neurosurgery, University Hospitals Birmingham, Birmingham, UK; \\ ${ }^{b}$ Department of Neurology, University Hospitals Birmingham, Birmingham, UK
}

\section{Keywords}

Foramen magnum decompression · Tonsillar herniation · Meningitis · Hydrocephalus

\section{Abstract}

Tonsillar herniation and coning is a rare and often late presentation of meningoencephalitis, and is associated with poor neurological outcome. We report the case of a 16-year-old female who presented unresponsive with radiological evidence of tonsillar herniation secondary to meningoencephalitis. She underwent an emergency foramen magnum decompression and C1 laminectomy with full recovery and no residual neurological deficit.

(C) 2018 The Author(s)

Published by S. Karger AG, Basel 


\section{Case Reports in Neurology}

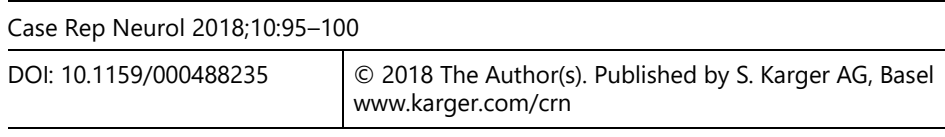

Afshari et al.: Emergency Foramen Magnum Decompression for Tonsillar Herniation Secondary to Meningoencephalitis

\section{Introduction}

Tonsillar herniation is a catastrophic and late presentation of meningoencephalitis, and is associated with a poor neurological outcome. The pathophysiology of tonsillar descent following meningoencephalitis is not fully understood but likely to be due to global cerebral swelling.

There are currently no clinical guidelines regarding surgical management of meningoencephalitis-related tonsillar herniation. The mainstay treatment for meningoencephalitis is antimicrobial treatments with tonsillar herniation representing a late stage which is associated with poor prognosis. Surgical management of such cases is controversial and aims at relieving intracranial pressure by diverting cerebrospinal fluid (CSF) or removing direct pressure of cerebellar tonsils on the brainstem. Here, we report the case of a 16-year-old with meningoencephalitis-associated tonsillar herniation with full recovery following surgical intervention. We discuss the potential surgical strategies that may be considered in selected cases of herniation secondary to meningoencephalitis.

\section{Case History}

We report the case of a 16-year-old girl who presented initially to her local hospital emergency department with headache, vomiting, and hallucinations associated with photophobia and neck stiffness. She underwent an urgent head CT, which was normal. She was commenced on acyclovir and ceftriaxone on the day of admission, and she made a clinical improvement. A lumbar puncture performed $24 \mathrm{~h}$ after antimicrobial therapy was commenced, which revealed CSF cell count of 226 (200 lymphocytes, 6 polymorphs), raised protein $1.2 \mathrm{~g} / \mathrm{L}$, negative Gram stain and culture, negative viral polymerase chain reaction (PCR). CSF glucose was not sent. In light of a predominantly lymphocytic CSF and presumed viral meningitis with clinical improvement, antibiotics were stopped 4 days after treatment. Three days later, she had acute deterioration in the neurological status with no clear evidence of seizures with a drop in the Glasgow Coma Scale score from 15 to 7 (E1V1M5) requiring intubation. Antimicrobial treatment was recommenced with additional cover for listeria and tuberculosis bacterium (TB). An urgent MRI brain demonstrated evidence of tonsillar herniation and coning which was not present on her previous cranial imaging (Fig. 1).

In light of significant clinical and radiological deterioration, she was transferred to our unit for further treatment. On arrival, she had equal and bilaterally reactive pupils to light. She underwent emergency insertion of an external ventricular drain (EVD) and foramen magnum decompression and C1 arch laminectomy. Postoperative MRI demonstrated satisfactory decompression of the foramen magnum (Fig. 2).

She was extubated on day 2 with removal of the EVD on day 11 postoperatively. Repeat CSF sampling from the EVD remained culture negative, as well as negative for $16 \mathrm{~S}$ ribosomal protein, TB PCR, and an extensive viral PCR screen. TB treatment was discontinued following negative TB PCR results. She made a full recovery with no neurological deficit. She was discharged following completion of a full course of intravenous antibiotics. 


\section{Case Reports in Neurology}

\section{Discussion}

In this article, we report the case of a 16-year-old girl who presented with tonsillar herniation secondary to meningoencephalitis. Surgical management of such cases poses a significant clinical dilemma as they are often associated with high morbidity and mortality. There are currently no guidelines regarding surgical management of such cases and intravenous antimicrobials are the mainstay treatment strategy for meningoencephalitis.

The pathophysiology of tonsillar herniation in meningoencephalitis is not fully understood but likely to be related to diffuse brain swelling and increased intracranial pressure with subsequent tonsillar descent leading to obstruction of CSF flow at the craniocervical junction. Raised protein and poor absorption of CSF is another potential mechanism of raised intracranial pressure in meningoencephalitis cases; however, in this case CSF protein was only raised to $1.2 \mathrm{~g} / \mathrm{L}$.

Clinical deterioration of the patient coincided with the evidence of new tonsillar herniation on brain MRI which was absent in her previous cranial imaging excluding pre-existing Chiari malformation. In addition, neurological deterioration was noted after stopping antibiotics in local hospital based on CSF cellular composition (predominantly lymphocytosis) with assumption of viral meningitis aetiology. Subsequent deterioration may therefore have been related to incompletely treated bacterial meningitis. CSF cultures and PCR (including 16s ribosomal DNA) and viral screens were all negative in this case. However, PCR for 16S ribosomal DNA has been shown to have a higher yield in incompletely treated or culturenegative bacterial meningitis [1].

Although supratentorial decompressive craniectomy has been previously reported for encephalitis, particularly in the context of viral herpes encephalitis, emergency foramen magnum decompression for tonsillar herniation in meningoencephalitis is extremely rare [2]. A review of the literature revealed only one previously reported case of foramen magnum decompression for meningoencephalitis-related tonsillar herniation in addition to our case [3]. Both cases demonstrated acute deterioration of the neurological status requiring intubation. The characteristics of the two cases have been summarised in Table 1.

Both cases underwent emergency insertion of an EVD to allow CSF diversion and the relief of intracranial pressure followed by foramen magnum decompression.

In the case reported by Fayeye et al. [3], herniated tonsils were resected subpially. In our case, tonsils were only reduced in size using bipolar cautery. Functional recovery in both cases is of particular interest. In the case reported by Fayeye et al. [3], the patient initially demonstrated evidence of tetraplegia and locked-in state postoperatively with gradual improvement to full recovery within 6 months [3]. In our case, the neurological recovery was faster. This may be due to the earlier presentation and decompression in our case.

The optimal surgical intervention if at all, in such cases is debatable. Surgical options include EVD as a sole procedure to relieve supratentorial compartment pressure. In certain cases, e.g. in patients with hydrocephalus, this procedure can be effective in controlling intracranial pressure and preventing coning. An alternative approach would be to reduce the supratentorial compartment with EVD with additional foramen magnum decompression to allow dis-impaction of the tonsils and relief of direct pressure on the brainstem. In the case reported here, ventricular CSF volume in the context of diffuse brain swelling was deemed to be too small to allow dis-impaction of cerebellar tonsils solely by EVD drainage. In addition, 
in the context of clinical deterioration and radiological coning, use of initial EVD as a single procedure ran the risk of brainstem ischaemia if CSF EVD drainage strategy failed, which would have made foramen magnum decompression futile as a second step. Therefore, a combined strategy was used to maximise her chances of responding to surgical intervention and to restore craniocervical junction CSF flow.

Surgical procedures therefore aim at relieving intracranial pressure and brainstem compression to allow patient stabilisation and continuation of antimicrobial therapy to treat the underlying infective cause. More research on the pathophysiology of this condition is required to guide us regarding optimal intervention.

In summary, meningoencephalitis can in rare cases present with tonsillar herniation. The mainstay treatment of meningoencephalitis is intravenous antimicrobial therapy. However, in cases of tonsillar herniation with reactive pupils and rapid access to the neurosurgical unit, surgical intervention may be considered as a potential strategy to restore craniocervical junction CSF flow.

\section{Statement of Ethics}

The patient has given full consent for publication of this article.

\section{Disclosure Statement}

The authors declare that they have no conflicts of interest.

\section{Funding Sources}

This work did not receive any specific grant from funding agencies.

\section{References}

1 Pandit L, Kumar S, Karunasagar I, Karunasagar I: Diagnosis of partially treated culture-negative bacterial meningitis using 16S rRNA universal primers and restriction endonuclease digestion. J Med Microbiol 2005;54:539-542.

-2 Pérez-Bovet J, Garcia-Armengol R, Buxó-Pujolràs M, Lorite-Díaz N, Narváez-Martínez Y, Caro-Cardera JL, Rimbau-Muñoz J, Joly-Torta MC, Castellví-Joan M, Martín-Ferrer S: Decompressive craniectomy for encephalitis with brain herniation: case report and review of the literature. Acta Neurochir (Wien) 2012;154:1717-1724.

-3 Fayeye O, Pettorini BL, Smith M, Williams H, Rodrigues D, Kay A: Meningococcal encephalitis associated with cerebellar tonsillar herniation and acute cervicomedullary injury. Br J Neurosurg 2013;27:513515. 


\section{Case Reports in Neurology}

\begin{tabular}{l|l}
\hline Case Rep Neurol 2018;10:95-100 \\
\hline DOI: 10.1159/000488235 & $\begin{array}{l}\text { (c) 2018 The Author(s). Published by S. Karger AG, Basel } \\
\text { www.karger.com/crn }\end{array}$ \\
\hline
\end{tabular}

Afshari et al.: Emergency Foramen Magnum Decompression for Tonsillar Herniation Secondary to Meningoencephalitis
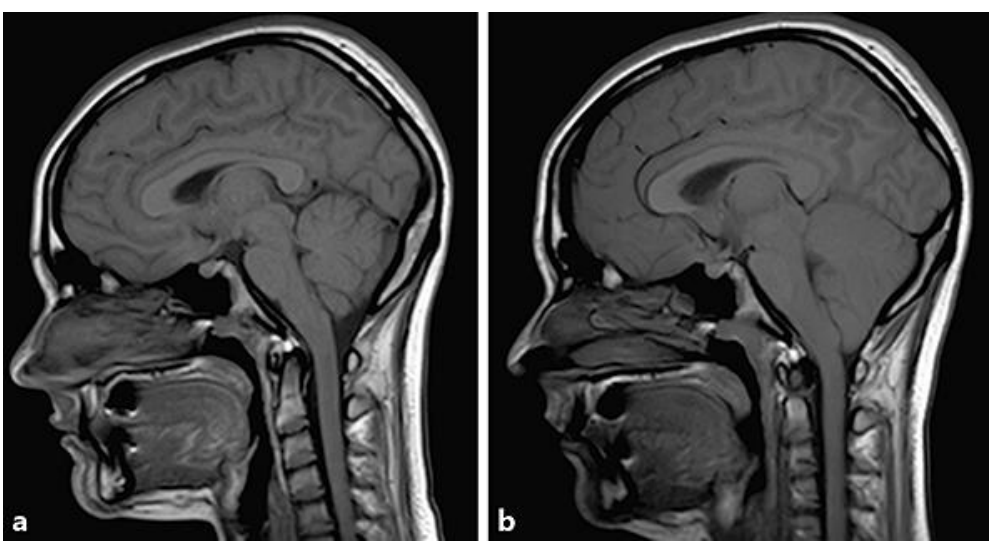

Fig. 1. a Sagittal T1 MRI brain prior to neurological deterioration. b Repeat MRI brain following neurological deterioration demonstrating new tonsillar herniation.
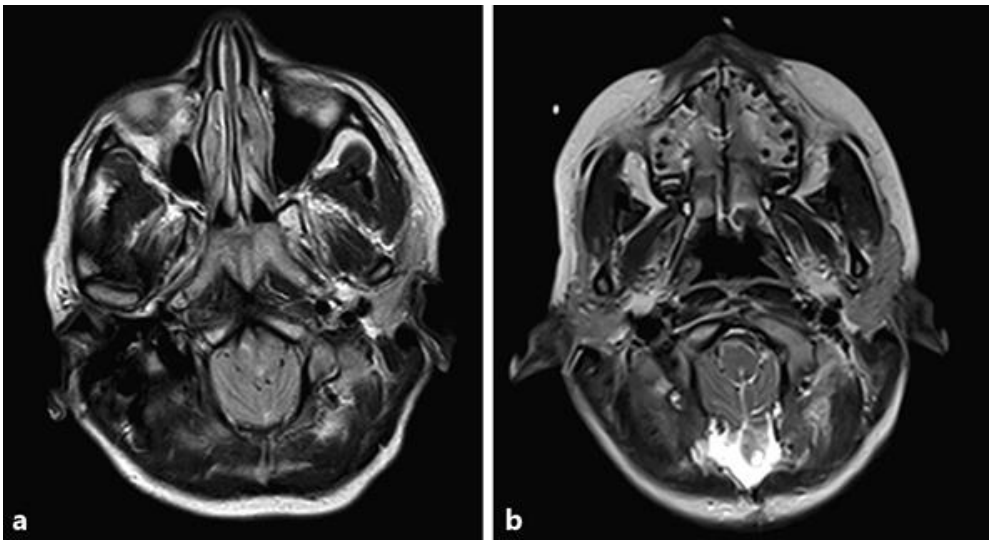

Fig. 2. Axial T2 MRI brain before (a) and after (b) foramen magnum decompression and C1 laminectomy. 
Afshari et al.: Emergency Foramen Magnum Decompression for Tonsillar Herniation Secondary to Meningoencephalitis

Table 1. Characteristics of two reported cases of foramen magnum decompression for tonsillar herniation from meningoencephalitis

\begin{tabular}{|c|c|c|c|c|c|c|c|}
\hline Pathology & Age/sex & $\begin{array}{l}\text { Presentation } \\
\text { (acute/ } \\
\text { subacute) }\end{array}$ & Imaging & $\begin{array}{l}\text { Timing of intervention from } \\
\text { acute deterioration }\end{array}$ & Surgery & $\begin{array}{l}\text { Neurological } \\
\text { outcome }\end{array}$ & $\begin{array}{l}\text { First au- } \\
\text { thor [Ref.], } \\
\text { year }\end{array}$ \\
\hline Meningoencephalitis & $13 / \mathrm{F}$ & acute & $\begin{array}{l}\text { tonsillar } \\
\text { herniation } \\
(20 \mathrm{~mm})\end{array}$ & within $24 \mathrm{~h}$ & $\begin{array}{l}\text { EVD+ } \\
\text { FMD+ } \\
\text { tonsillar } \\
\text { resection }\end{array}$ & full recovery & $\begin{array}{l}\text { Fayeye [3], } \\
2012\end{array}$ \\
\hline Meningoencephalitis & $16 / \mathrm{F}$ & acute & $\begin{array}{l}\text { tonsillar } \\
\text { descent } \\
(12 \mathrm{~mm})\end{array}$ & within $24 \mathrm{~h}$ & $\begin{array}{l}\text { EVD+ } \\
\text { FMD+ } \\
\text { tonsillar } \\
\text { cautery }\end{array}$ & full recovery & this study \\
\hline
\end{tabular}

EVD, external ventricular drain; FMD, foramen magnum decompression. 